\title{
PENGARUH HARGA TERHADAP KEPUTUSAN PEMBELIAN DENGAN SELERA SEBAGAI VARIABEL INTERVENING (Studi Kasus Pada Perusahaan Daerah Pasar Horas Jaya Pematangsiantar)
}

\author{
Mega Romauly Tampubolon ${ }^{1)}$, Sumaizar ${ }^{2)}$ \\ ${ }^{1)}$ Program Studi Manajemen, Sekolah Tinggi Akuntansi Dan Manajemen Indonesia \\ email.tampubolonmega75@gmail.com \\ ${ }^{2}$ Program Studi Akuntansi, Sekolah Tinggi Akuntansi Dan Manajemen Indonesia \\ Email: sumaizar@gmail.com
}

\begin{abstract}
Abstarct
The development of the times is growing rapidly marked by increasingly sophisticated technology. The formulation of the problem in this study is how the influence of prices on purchasing decisions with taste as an intervening variable. This research aims to determine the price of purchasing decisions with taste as an intervening variable. The research design used by the author is field research, where the research was conducted at the Pematangsiantar Horas Jaya Regional Corporation, the population that is the Sword in the Horas Market in the Horas Regional Company. The sampling technique uses purposive sampling with the criteria of shoe traders as a research sample of 56 traders. Data analysis techniques using simple regression, hypothesis testing, coefficient of determination, and path analysis. The results of the study showed that the price had a positive and significant influence on purchasing decisions in the Regional Corporation of Horas Jaya, Pematangsiantar City, and taste was an intervening variable, or by adding a variable of tastes the price effect on purchasing decisions was higher.
\end{abstract}

Keywords: Price, Taste, Purchase Decision

\section{PENDAHULUAN}

Perkembangan zaman kian harikian berkembang pesat ditandai dengan tekhnologi yang semakin canggih. Seiring dengan itu juga berdampak terhadap pertumbuhan ekonomi, khususnya dalam bidang eceran maupun grosir. Hal ini ditandai dengan pencapaian kinerja pedagang besar dan eceran meningkat didukung oleh permintaan domestik.

Kebutuhan manusia sangatlah beragam, untuk memenuhi kebutuhan mereka yang tak terbatas dengan kemampuan yang berbeda- beda dalam setiap individunya, maka muncullah pasar. Pasar merupakan ala yang memungkinkan individu berinteraksi untuk membeli dan menjual barang atau jasa tertentu [1], [2].

Daerah kota Pematangsiantar memiliki pasar tradisional terbesar salah satunya yang bernama Pasar Horas. Pasar tradisional yang dimiliki Kota Horas Pematangsiantar sejak berpuluh tahun lalu. Kedua pasar itu kini masih kokoh berdiri di tengah-tengah meningkatnya laju pertumbuhan ekonomi dan pembangunan di Kota Pematangsiantar. Pasar Horas terdiri dari beberapa pedagang, salah satunya adalah pedangang sepatu.

Fenomena keputusan pembelian yang terjadi pada Pasar Horas Pematangsiantar yang masih belum optimal dilihat dari dimensi keputusan pembelian dimana masih ada pelanggan yang sulit untuk menentukan keputusan dengan membeli dikarenakan masih terdapat pelanggan yang membandingbandingkan harga dengan penjualan online seperti lazada, shopie, dll.

Pada umumnya masyarakat sekarang tergolong masyarakat yang pemilih, oleh karena itu penjual harus cerdas dan tanggap akan kebutuhan masyarakat serta memperhatikan harga untuk nilai yang didapat ketika membayar suatu barang atau jasa suatu pilihan harga yang terjangkau dengan kualitas yang tidak kalah dengan harga mahal maka konsumen akan lebih memilih untuk membeli barang tersebut tanpa berpikir panjang.

Pencapaian yang lebih tinggi dibandingkan dengan tahun sebelumnya tidak 
DOI 10.37600/ekbi.v3i2.185

terlepas oleh pengaruh pendapatan perkapita penduduk serta jumlah penduduk yang bertambah. Hal penting dalam memasarkan produk yaitu harga. Dimana harga adalah sejumlah uang yang dibutuhkan untuk mendapatkan sejumlah kombinasi dari produk beserta pelayanannya [3]. Agar dapat sukses dalam memasarkan suatu barang atau jasa, setiap perusahaan harus menetapkan harganya secara tepat. Harga merupakan satu- satunya unsur bauran pemasaran yang memberikan pemasukan atau pendapatan bagi perusahaan.

Dari sudut pandang konsumen, harga seringkali digunakan sebagai indikator nilai bilamana harga tersebut dihubungkan dengan manfaat yang dirasakan atas suatu barang atau jasa [4]. Fenomena harga yang terjadi pada Pasar Horas terdapat pada dimensi keterjangkauan harga, hal ini dapat dibuktikan masih terdapat beberapa pelanggan yang mengatakan bahwa harga yang ditawarkan masih terlalu tinggi jika dibandingkan dengan melakukan penjualan online.

Faktor selanjutnya yaitu selera konsumen. Selera merupakan kegiatan seseorang untuk membeli suatu barang atau jasa. Selera konsumen pada umumnya berubah dari waktu ke waktu [2]. Meningkatkan selera seseorang terhadap suatu barang tertentu pada umumnya berakibat naiknya jumlah permintaan terhadap barang tersebut, begitu pula sebaliknya menurunnya selera konsumen terhadap suatu barang tertentu pada umumnya berakibat berkurangnya jumlah permintaan terhadap barang tersebut.

Rumusan masalah dalam penelitian ini adalah bagaimana pengaruh harga terhadap keputusan pembelian dengan selera sebagai variabel intervening. Maka tujuan penelitian ini adalah untuk mengetahui harga terhadap keputusan pembelian dengan selera sebagai variabel intervening.

\section{URAIAN TEORITIS Manajemen}

Manajemen merupakan suatu kegiatan yang dilakukan untuk mengatur suatu proses yang dilakukan oleh suatu kelompok orang atau organisasi dalam mencapai suatu tujuan organisasi dengan cara memanfaatkan segala sumber daya yang ada. Manajemen juga dapat dilihat sebagai sebuah disiplin ilmu yang telah mengajarkan tentang proses untuk memperoleh suatu tujuan organisasi melalui usaha bersama dengan sejumlah orang di dalam suatu organisasi.

Manajemen merupakan aktivitasaktivitas koordinasi dan pengawasan terhadap pekerjaan orang lain sehingga pekerjaan tersebut diselesaikan secara efektif dan efisien [5]. Maka dapat menyimpulkan bahwa manajemen merupakan suatu rangkaian aktivitas yang terkoordinasi untuk mencapai sasaran organisasi dengan cara efektif dan efisien, melalui kegiatan perencanaan, pengorganisasian, kepemimpinan dan pengendalian sumber daya.

\section{Manajemen Pemasaran}

Pemasaran merupakan suatu kegiatan utama yang harus dilakukan oleh suatu perusahaan, baik itu perusahaan jasa ataupun barang dalam upaya untuk mempertahankan kelangsungan hidup usahanya melalui kegiatan pemasaran, perusahaan akan mampu memperkenalkan produknya di dalam kehidupan masyarakat [6].

Pemasaran adalah proses dimana perusahaan menciptakan nilai bagi pelanggan dan membangun hubungan pelanggan yang kuat untuk menangkap nilai dari pelanggan sebagai imbalannya [7]. Maka dapat disimpulkan bahwa pemasaran merupakan suatu kegiatan yang menciptakan nilai bagi pelanggan,membangun hubungan dengan pelanggan dan memenuhi kebutuhan pelanggan serta memperkenalkan produk atau jasa yang telah diproduksi oleh perusahaan, sehingga masyarakat dengan mudah mengenal produk yang dipasarkan.

\section{Keputusan Pembelian}

Keputusan pembelian merupakan suatu tindakan yang akan diambil oleh seorang konsumen dalam membeli produk atau jasa. Pengambilan keputusan dalam pembelian merupakan suatu proses dimana seorang konsumen akan memilih beberapa alternatif dalam menyelesaikan masalah dengan tindak lanjut yang nyata. Keputusan pembelian merupakan suatu proses pengambilan keputusan akan pembelian yang mencakup penentuan apa yang akan dibeli atau tidak melakukan pembelian dan keputusan itu diperoleh dari kegiatan-kegiatan sebelumnya [3]. Adapun beberapa dimensi dalam proses keputusan pembelian yaitu pengenalan masalah, pencarian informasi, evaluasi 
alternatif, keputusan pembelian, dan perilaku pasca pembelian [5].

\section{Harga}

Di suatu perusahaan harus jelas dalam menentukan harga jual serta harus jelas dalam menentukan tujuan yang akan dicapainya. Harga adalah suatu nilai uang yang harus dibayarkan oleh seorang konsumen kepada penjual atas barang atau jasa yang telah dibelinya [8]. Tujuan penetapan harga agar perusahaan memperoleh laba yang diinginkan dan dapat berjalan secara efektif dan efisien demi kelangsungan hidup perusahaan. Fungsi harga dalam membantu para pembeli untuk memutuskan cara memperoleh manfaat atau utilitas tertinggi yang diharapkan berdasarkan biaya. Adapun harga yang dapat diukur dari dimensi keterjangkauan harga, potongan harga, dan cara pembayaran [9].

\section{Selera}

Selera merupakan kegiatan seseorang untuk membeli suatu barang atau jasa. Selera konsumen pada umumnya berubah pada waktu ke waktu. Meningkatnya selera terhadap suatu barang tertentu pada umumnya berakibat naiknya jumlah permintaan terhadap barang tersebut begitu pula sebaliknya menurunnya selera konsumen terhadap suatu barang tertentu pada umumnya berakibat berkurangnya jumlah permintaan terhadap barang tersebut [3]. Di mana selera ini akan menjadi langkah awal terbentuknya perilaku konsumen atas suatu produk. Pada dasarnya selera konsumen ini timbul secara individual yang relatif stabil dapat dijadikan keputusan konsumen pada suatu produk [10].

Hipotesis merupakan jawaban sementara terhadap rumusan masalah penelitian, di mana rumusan masalah penelitian telah dinyatakan dalam bentuk pertanyaan [11]. Adapun hipotesis yang diajukan sebagai berikut:

1. Harga berpengaruh terhadap Keputusan Pembelian.

2. Harga berpengaruh terhadap Keputusan Pembelian melalui selera

Kerangka Konseptual dalam penelitian ini adalah:

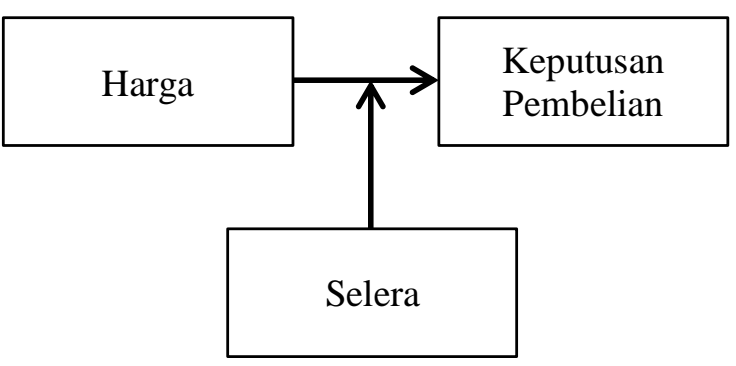

Gambar 1. Kerangka Konseptual

\section{METODE PENELITIAN}

Jenis Penelitian

Pendekatan asosiatif digunakan dalam penelitian ini. Desain penelitian yang digunakan penulis adalah Penelitian lapangan (Field Research). Data yang digunakan penelitian ini menggunakan data primer dengan mengumpulkan data dan wawancara kepada pedagang pada Perusahaan Daerah Horas Jaya.

\section{Tempat Penelitian}

Tempat penelitian dilakukan pada Perusahaan Daerah Horas Jaya.

\section{Ruang Lingkup}

Ruang lingkup penelitian yang diteliti berhubungan dengan harga sebagai variabel bebas (X) dengan dimensi keterjangkauan harga, potongan harga, dan cara pembayaran. Pada Keputusan Pembelian (Y) dengan dimensi pengenalan masalah, pencarian informasi, evaluasi alternatif, keputusan pembelian, dan perilaku pasca pembelian. Variabel Intervening Selera (Z) kesan konsumen dalam pembelian dan nilai guna produk.

\section{Populasi dan Sampel}

Populasi yaitu Pedangang di Pasar horas

Pada Perusahaan Daerah Horas. Teknik pengambilan sampel menggunakan purposive sampling dengan kriteria pedagang sepatu sebagai sampel penelitian yang berjumlah 56 pedagang.

\section{Prosedur}


Data kauntitatif digunakan dalam penelitian ini. Data kuantitatif diperoleh didapatkan jawaban responden mengenai harga, keputusan pembelian dan selera.

\section{Teknik Pengumpulan Data}

Teknik pengumpulan data dengan metode dokumentasi dengan cara mengumpulkan data dan informasi melalui buku-buku karangan ilmiah, referensi dan menggunakan media elektronik untuk searching. Sebelum melakukan pengumpulan data dengan kuisioner dilakukan uji intrusmen data, dengan uji validitas, dan reliabilitas.

Tabel 1. Hasi Uji Validitas

\begin{tabular}{ccccc}
\hline \multicolumn{2}{c}{ Variabel } & rhitung & rkritis & Hasil Uji \\
\hline \multirow{4}{*}{ Harga $(\mathbf{X})$} & $\mathrm{X}_{1}$ & $\mathbf{0 , 5 4 5}$ & 0,3 & Valid \\
& $\mathrm{X}_{2}$ & $\mathbf{0 , 4 7 4}$ & 0,3 & Valid \\
& $\mathrm{X}_{3}$ & $\mathbf{0 , 4 7 4}$ & 0,3 & Valid \\
& $\mathrm{Y}_{1}$ & $\mathbf{0 , 4 5 0}$ & 0,3 & Valid \\
Keputusan & $\mathrm{Y}_{2}$ & $\mathbf{0 , 5 5 1}$ & 0,3 & Valid \\
Pembelian & $\mathrm{Y}_{3}$ & $\mathbf{0 , 4 5 0}$ & 0,3 & Valid \\
(Y) & $\mathrm{Y}_{4}$ & $\mathbf{0 , 5 5 1}$ & 0,3 & Valid \\
& $\mathrm{Y}_{5}$ & $\mathbf{0 , 4 7 4}$ & 0,3 & Valid \\
Selera $(Z)$ & $\mathrm{Z}_{1}$ & $\mathbf{0 , 4 7 4}$ & 0,3 & Valid \\
& $\mathrm{Z}_{2}$ & $\mathbf{0 , 4 7 7}$ & 0,3 & Valid \\
\hline
\end{tabular}

Sumber: Pengolahan Data (2020)

Berdasarkan tabel di atas diketahui semua indikator variabel dalam penelitian ini adalah valid.

Tabel 2. Hasil Uji Realibilitas

\begin{tabular}{ccc}
\hline $\begin{array}{c}\text { Cronbach's } \\
\text { Alpha }\end{array}$ & N of item & Hasil Uji \\
\hline $\mathbf{0 , 9 5 3}$ & 3 & Reliabel \\
$\mathbf{0 , 9 5 2}$ & 5 & Reliabel \\
$\mathbf{0 , 9 5 3}$ & 2 & Reliabel \\
\hline
\end{tabular}

Sumber: Pengolahan Data (2020)

Dari tabel di atas disimpulkan indikator variabel dalam penelitian ini adalah reliabel.

\section{Teknik Analisis Data}

Teknik analisis data ialah uji kualitas data, uji Asumsi Klasik, analisis regresi linear sederhana, uji hipotesis, dan koefesien determinasi, analisis jalur.

\section{HASIL DAN PEMBAHASAN}

HASIL

\section{Uji Asumsi Klasik}

Hasil uji normalitas menggunakan uji Kolmogorov-Smirnov, sebagai berikut:
Tabel. 3 Hasil Uji Normalitas One-Sample Kolmogorov-Smirnov Test

\begin{tabular}{|ll|r|}
\hline & & \multicolumn{2}{|c|}{$\begin{array}{c}\text { Unstandardized } \\
\text { Residual }\end{array}$} \\
\hline Normal & Mean & 56 \\
Parametersa,b & Std. &, 0000000 \\
& Deviation & 1,79924748 \\
Most & Absolute &, 108 \\
Extreme & Positive &, 058 \\
Differences & Negative &,- 108 \\
Kolmogorov-Smirnov Z &, 807 \\
Asymp. Sig. (2-tailed) &, 533 \\
\hline
\end{tabular}

Sumber: Pengolahan Data (2020)

Berdasarkan tabel di atas dapat dilihat unstandardized Residual, 0,533 > 0,05. Maka dpat disimpulkan seluruh variabel berdistribusi normal.

\section{Uji Multikolineritas}

Uji multikolineritas menggunakan Varince Inflation Factor (VIF), sebagai berikut:

\section{Tabel 4. Hasil Uji Multikolineritas} Coefficients $^{\mathrm{a}}$

\begin{tabular}{|l|r|}
\hline Model & \multicolumn{2}{|c|}{ Collinearity Statistics } \\
\cline { 2 - 2 } & \multicolumn{2}{|c|}{ VIF } \\
\hline (Constant) & 1,168 \\
1 Harga & 1,168 \\
Selera & \\
\hline
\end{tabular}

a. Dependent Variable: Keputusan Pembelian

Sumber: Pengolahan Data (2020)

Dari tabel diatas diperoleh nilai VIF untuk seluruh variabel < 10 , artinya tidak terjadi gejala multikolineritas.

\section{Uji Heterokedasitas}

Uji heterokedasitas diuji menggunakan metode grafik, dengan hasil sebagai berikut: 
DOI 10.37600/ekbi.v3i2.185

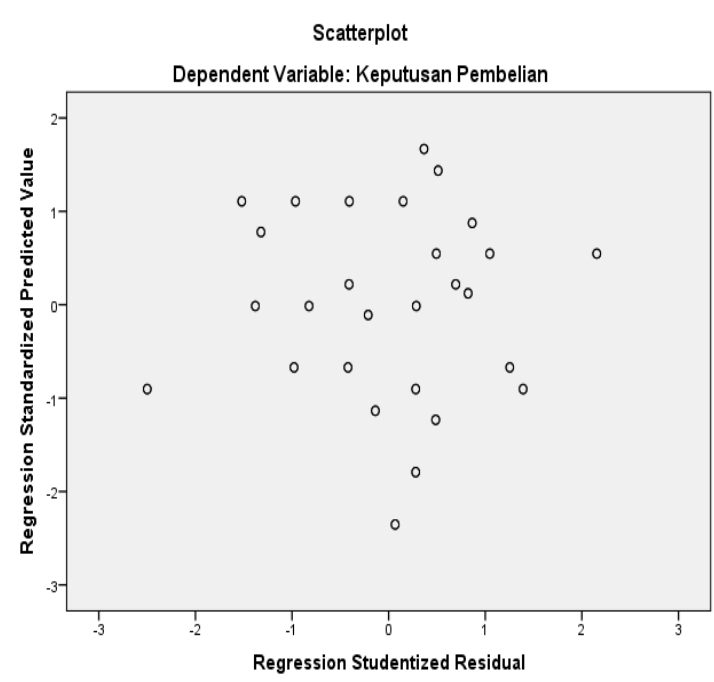

Gambar 2. Grafik Scatreeplot

Dari gambar grafik scatterplot diatas terlihat menyebar secara acak, maka dinyatakan tidak terjadi gejala heterokedastisitas.

\section{Uji Regresi Linaer Sederhana}

Untuk mengetahui pengaruh antar variabel digunakan analisis regresi linear sederhana, hasilnya sebagai berikut:

\section{Tabel 5. Hasil Regresi Linear Sederhana} Coefficients $^{\mathrm{a}}$

\begin{tabular}{|c|c|c|c|}
\hline \multirow[t]{2}{*}{ Model } & \multicolumn{2}{|c|}{$\begin{array}{c}\text { Unstandardized } \\
\text { Coefficients }\end{array}$} & $\begin{array}{l}\text { Standardized } \\
\text { Coefficients }\end{array}$ \\
\hline & $B$ & $\begin{array}{l}\text { Std. } \\
\text { Error }\end{array}$ & Beta \\
\hline $1 \begin{array}{ll}\text { (Constant) } \\
\text { Harga }\end{array}$ & $\begin{array}{l}9,237 \\
2,721\end{array}$ & $\begin{array}{r}1,968 \\
, 170\end{array}$ & ,499 \\
\hline
\end{tabular}

a. Dependent Variable: Keputusan Pembelian

Sumber: Pengolahan Data (2020)

Berdasarkan tabel di atas, diperoleh model persamaan regresi, sebagai berikut:

$$
\hat{\mathbf{Y}}=\mathbf{9 , 2 3 7}+\mathbf{2 , 7 2 1}
$$

Persamaan regresi diperoleh hasil harga berpengaruh positif terhadap keputusan pembelian pada Perusahaan Daerah Pajak Horas Jaya Kota Pematangsiantar.

\section{Koefesien Determinasi}

Hasil koefesien determinasi, sebagai berikut:
Tabel 6. Hasil Koefesien Determinasi Model Summary

\begin{tabular}{|l|c|r|r|c|}
\hline Model & $R$ & $\begin{array}{c}R \\
\text { Square }\end{array}$ & $\begin{array}{c}\text { Adjusted } \\
\mathrm{R} \\
\text { Square }\end{array}$ & $\begin{array}{r}\text { Std. Error of } \\
\text { the Estimate }\end{array}$ \\
\hline 1 &, $799^{\mathrm{a}}$ &, 649 &, 235 & 1,84960 \\
\hline
\end{tabular}
a. Predictors: (Constant), Harga
b. Dependent Variable: Keputusan Pembelian

Sumber: Pengolahan Data (2020)

Berdasarkan tabel di atas diperoleh nilai koefisien determinasinya (Adjusted $R$ square) sebesar 0,649 atau $64,9 \%$, hal ini berarti harga dapat mempengaruhi variabel keputusan pembelian dan sisanya $35,1 \%$ dipengaruhi oleh variabel lain yang tidak dibahas dalam penelitian ini.

\section{Uji Hipotesis (Uji t)}

Untuk mengetahui pengaruh masingmasing variabel digunakan uji t. Hasil uji t, sebagai berikut:

\section{Tabel 7. Hasil Uji t}

Coefficients $^{a}$

\begin{tabular}{|l|r|r|}
\hline Model & $\mathrm{t}$ & \multicolumn{2}{|c|}{ Sig. } \\
\hline \multirow{2}{*}{$\begin{array}{l}\text { (Constant) } \\
\text { Harga }\end{array}$} & 4,693 &, 000 \\
\hline
\end{tabular}

a. Dependent Variable: Keputusan Pembelian Sumber: Pengolahan Data (2020)

Berdasarkan hasil uji t, diperoleh $t_{\text {tabel }}$ sebesar 2,004, maka pengaruh harga, dengan $t_{\text {hitung }}$ sebesar 4,232, dan nilai signifikan $0,000<0,05$, artinya harga berpengaruh positif dan signifikan terhadap keputusan pembelian pada Perusahaan Daerah Pajak Horas Jaya Kota Pematangsiantar.

\section{Analisis Jalur}

Analisis jalur digunakan untuk mengetahui apakah variabel Selera merupakan variabel yang dapat memediasi hubungan antara harga terhadap keputusan pembelian.

Tabel 8. Hasil Analisis Jalur R Square Model Summary ${ }^{b}$

\begin{tabular}{|l|c|r|r|c|}
\hline Model & $\mathrm{R}$ & $\begin{array}{c}\mathrm{R} \\
\text { Square }\end{array}$ & $\begin{array}{r}\text { Adjusted } \\
\mathrm{R} \text { Square }\end{array}$ & $\begin{array}{c}\text { Std. Error of the } \\
\text { Estimate }\end{array}$ \\
\hline 1 &, $829^{\mathrm{a}}$ &, 679 &, 372 & 1,94750 \\
\hline
\end{tabular}

a. Predictors: (Constant), Harga, Keputusan Pembelian

b. Dependent Variable: Selera

Sumber: Pengolahan Data (2020) 
DOI 10.37600/ekbi.v3i2.185

\section{Tabel 9. Hasil Analisis Jalur Coefficients Regresi}

coefficients $^{a}$

\begin{tabular}{|c|r|r|r|r|r|}
\hline Model & \multicolumn{2}{|c|}{$\begin{array}{c}\text { Unstandardiz } \\
\text { ed } \\
\text { Coefficients }\end{array}$} & $\begin{array}{c}\text { Standar } \\
\text { dized } \\
\text { Coeffici } \\
\text { ents }\end{array}$ & $\mathrm{t}$ & Sig. \\
\cline { 2 - 4 } & $\mathrm{B}$ & $\begin{array}{c}\text { Std. } \\
\text { Error }\end{array}$ & Beta & & \\
\hline Constant) & 4,273 & $\mathbf{1 , 2 0 5}$ & & $\mathbf{3 , 5 4 6}$ &, 001 \\
Harga &, 196 &, 101 & $\mathbf{2 7 8}$ & 1,930 & $\mathbf{0 5 9}$ \\
Keputusan &, 099 &, 070 & $\mathbf{2 0 3}$ & $\mathbf{1 , 4 1 0}$ & $\mathbf{, 1 6 4}$ \\
Pembelian & & & & \\
\hline
\end{tabular}

a. Dependent Variable: Selera

Sumber: Pengolahan Data (2020)

Koefisien-koefisien dan korelasi yang telah diperoleh pada analisis korelasi sebelumnya di atas dimasukkan ke dalam diagram analisis jalur sub-struktur sebagai berikut:

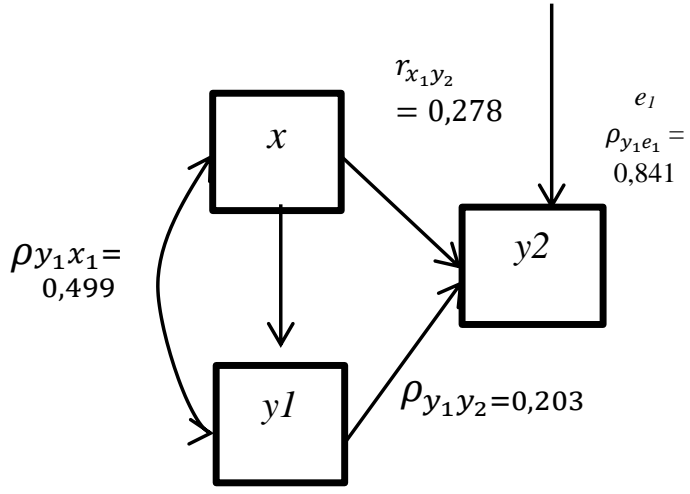

\section{Gambar 3. Hasil Pengujian Sub-struktur}

Dari gambar di atas terlihat besarnya hubungan antar variabel. Model persamaannya adalah: $\quad y_{2}=0.278 x+0.203 y_{1}+0.841$. Diketahu pengaruh langsung yang diperoleh dari x1 terhadap y2 sebesar 0,278. Sedangkan pengaruh tidak langsung $\mathrm{x}$ melalui $\mathrm{y} 1$ terhadap y2 adalah perkalian nilai yaitu: 0,499 $\mathrm{x} \quad 0,203=0,101$. Maka total pengaruh langsung dan tidak langsung diperoleh 0,278+ $0,101=0,379$.

Berdasarkan perhitungan tersebut diperoleh pengaruh tidak langsung sebsar 0,278 dan pengaruh tidak langsung sebesar 0,379 , yang berarti bahwa pengaruh tidak langsung lebih besar dibandingkan dengan nilai pengaruh langsung. Maka hal ini menunjukkan bahwa variabel selera merupakan variabel intervening, atau dengan menambahkan variabel selera maka pengaruh harga terhadap keputusan pembelian semakin tinggi.

\section{Pembahasan}

\section{Pengaruh Harga Terhadap Keputusan Pembelian}

Harga merupakan nilai uang yang dibayarkan atas pembelian produk atau jasa yang telah diterimanya. Dengan menerapkan harga perusahaan dapat memperoleh laba yang diinginkan dan dapat berjalan secara efektif dan efisien demi kelangsungan hidup perusahaan.

Dari hasil uji regresi linear sederhana diperoleh harga berpengaruh positif terhadap keputusan pembelian pada Perusahaan Daerah Pajak Horas Jaya Kota Pematangsiantar. Berdasarkan hasil uji nilai koefisien determinasinya (Adjusted $R$ square) sebesar 0,649 atau $64,9 \%$, hal ini berarti harga dapat mempengaruhi variabel keputusan pembelian dan sisanya $35,1 \%$ dipengaruhi oleh variabel lain yang tidak dibahas dalam penelitian ini.

Hasil uji hipotesis hasil uji t, diperoleh $t_{\text {tabel }}$ sebesar 2,004, maka pengaruh harga, dengan thitung sebesar 4,232, dan nilai signifikan $0,000<0,05$, artinya harga berpengaruh positif dan signifikan terhadap keputusan pembelian pada Perusahaan Daerah Pajak Horas Jaya Kota Pematangsiantar.

Hasil penelitian ini sejalan dengan penelitian yang dilakukan [3], [12], dan [8]. penulis menyimpulkan bahwa harga memiliki peranan yang penting dalam memepengaruhi keputusan. Untuk meningkatkan keputusan pembelian maka pedagang di Pasar horas Pada Perusahaan Daerah Horas dapat mengevaluasi kembali strategi harga yang telah dilakukan, dengan memberikan diskon pada saat tertentu dan pada saat konsumen membeli dalam jumlah banyak.

\section{Pengaruh Harga Terhadap Keputusan Pembelian Melalui Selera Sebagai Variabel Intervening}

Selera konsumen pada umumnya berubah pada waktu ke waktu. Meningkatnya selera terhadap suatu barang tertentu pada umumnya berakibat naiknya jumlah permintaan terhadap barang tersebut begitu pula sebaliknya menurunnya selera konsumen terhadap suatu barang tertentu pada umumnya berakibat berkurangnya jumlah permintaan terhadap barang tersebut.

Hasil uji analisis jalur koefisienkoefisien dan korelasi yang telah diperoleh 
DOI 10.37600/ekbi.v3i2.185

pengaruh tidak langsung lebih besar dibandingkan dengan nilai pengaruh langsung. Maka hal ini menunjukkan bahwa variabel selera merupakan variabel intervening, atau dengan menambahkan variabel selera maka pengaruh harga terhadap keputusan pembelian semakin tinggi.

Hal ini sejalan dengan penelitian yang dilakukan [2] dan [13][14]. Berdasarkan penelitian ini maka penulis dapat menyimpulkan bahwa pengaruh harga terhadap keputusan pembeli akan semakin meningkat jika menambahkan variabel selera. Maka pedagang di Pasar horas Pada Perusahaan Daerah Horas tetap memperhatikan selera pada saat ini yang disukai oleh konsumennya. Konsumen yang menyukai produk sesuai dengan selera akan membeli produk tersebut.

\section{KESIMPULAN DAN SARAN}

\section{Kesimpulan}

Dari hasil pengujian hipotesis dan evaluasi yang telah dijabarkan oleh penulis, maka dapat ditarik kesimpulan harga berpengaruh positif terhadap keputusan pembelian pada Perusahaan Daerah Pajak Horas Jaya Kota Pematangsiantar. Hasil uji hipotesis diperoleh harga berpengaruh positif dan signifikan terhadap keputusan pembelian pada Perusahaan Daerah Pajak Horas Jaya Kota Pematangsiantar. Dari hasil analisis nilai koefisien determinasinya (Adjusted $R$ square) sebesar 0,649 atau 64,9\%, hal ini berarti harga dapat mempengaruhi variabel keputusan pembelian dan sisanya $35,1 \%$ dipengaruhi oleh variabel. Hasil uji analisis jalur dipeoleh variabel selera merupakan variabel intervening, atau dengan menambahkan variabel selera maka pengaruh harga terhadap keputusan pembelian semakin tinggi

\section{Saran}

Berdasarkan kesimpulan dan hasil evaluasi penelitian yang telah dilakukan, maka penulis memberikan beberapa saran persepsi pasien dapat memberikan informasi Untuk meningkatkan keputusan pembelian maka pedagang di Pasar horas Pada Perusahaan Daerah Horas dapat mengevaluasi kembali strategi harga yang telah dilakukan, dengan memberikan diskon pada saat tertentu dan pada saat konsumen membeli dalam jumlah banyak, dan pedagang di Pasar horas Pada
Perusahaan Daerah Horas tetap memperhatikan selera pada saat ini yang disukai oleh konsumennya. Konsumen yang menyukai produk sesuai dengan selera akan membeli produk tersebut.

Sehubungan dengan keterbatasanketerbatasan yang ada pada penulis, penelitian ini masih jauh dari kesempurnaan dan masih terdapat kelemahan-kelemahan, serta belum dapat mengungkapkan seluruh variabel yang keputusan pembelian. Sebagai bahan masukan untuk penelitian selanjutnya, perlu memperbanyak variabel penelitian seperti, kualitas produk, kinerja, kepuasan, dan lainlain.

\section{REFERENSI}

\author{
A. A. LUBIS, "PENGARUH HARGA \\ DAN KUALITAS PRODUK \\ TERHADAP KEPUTUSAN \\ PEMBELIAN SURAT KABAR PADA \\ PT. SUARA BARISAN HIJAU \\ HARIAN ORBIT MEDAN," J. Ilm.
} Manaj. dan Bisnis, vol. 16, no. 02, pp. 1-11, 2015.

[2] R. V. Latmawati, Yulna Dewita Hia, "Pengaruh Harga, Kualitas produk, Selera Konsumen Terhadap Pembelian Ulang Beras Sipulau Di Kejorongan 3 Pangian Dengan Kepuasan Konsumen Sebagai Variabel Intervening (Studi Kasus Pada Toko Tuan Muda) Latmawati1," Repos. STKIP PGRI, pp. $1-9,2016$.

[3] J. I. Juliadi, "PENGARUH HARGA, PROMOSI, DAN SELERA KONSUMEN TERHADAP KEPUTUSAN MEMBELI HANDPHONE MERK OPPO DI GRIYA MATAHARI SINGOSAREN SURAKARTA," pp. 24-30, 2010.

[4] R. C. Puspita and S. Suryoko, "PENGARUH IKLAN, HARGA, DAN KEPERCAYAAN MEREK TERHADAP KEPUTUSAN PEMBELIAN KOSMETIK REVLON (Studi pada Mahasiswa S1 Universitas Diponegoro) Rahmilla Chairani Puspita 1 \& Sri Suryoko 2," pp. 1-8, 2017.

[5] P. Kotler and K. L. Keller, Manajemen Pemasaran, 13th ed. Jakarta: Erlangga, 2009.

[6] D. E. Putri, O. S. Sinaga, S. S. Agustina, H. P. Silitonga, and A. 
Sudirman, "Minat Kunjungan Ulang

Pasien yang Ditinjau dari Aspek

Persepsi dan Kepercayaan pada Klinik

Vita Medistra Pematangsiantar," vol. 8, pp. 41-46, 2020.

[7] Philip Kotler and G. Amstrong, Prinsip-Prinsip Pemasaran, 12th, Jilid ed. Jakarta: Erlangga, 2012.

[8] M. L. Saraswati, A. Pradhanawati, and W. Hidayat, "Pengaruh Desain Produk, Kualitas Produk, dan Harga Terhadap Keputusan Pembelian Pada Kampung Batik Wiradesa, Kabupaten Pekalongan," J. Ilmu Adm. Bisnis, vol. 4, no. 2, pp. 137-146, 2015.

[9] P. Kotler and G. Amstrong, Prinsipprinsip Pemasaran, 12th ed. Jakarta, 2008.

[10] A. R. M. Sirait, R. Budiman, and A. M. Deka, "PENGARUH FAKTOR HARGA, SELERA DAN KUALITAS PRODUK TERHADAP KEPUTUSAN KONSUMEN DALAM MEMBELI KAIN CORAK INSANG DI KOTA PONTIANAK," pp. 28-33.

[11] Sugiyono, Metodologi Penelitian Bisnis. Bandung: Alfabeta, 2010.

[12] R. Taroreh, "Promosi, Harga Dan Inovasi Pengaruhnya Terhadap Keputusan Pembelian Sepatu Futsal Nike Di Toko Akbar Ali Sport Manado," J. Ris. Ekon. Manajemen, Bisnis dan Akunt., vol. 2, no. 2, pp. 1381-1392, 2014, doi: 10.35794/emba.v2i2.4757.

[13] I. G. P. E. Suantara, M. Artana, and K. R. Suwena, "Pengaruh selera dan harga terhadap konsumen dalam pembelian sepeda motor Honda di Kabupaten Buleleng," J. Pendidik. Ekon. UNDIKSHA, vol. 4, no. 2, pp. 1-10, 2014.

[14] A. S. Tiefani, “ANALISIS FAKTORFAKTOR YANG MEMPENGARUHI MINAT BELI ULANG KONSUMEN PADA PT ANUGERAH AVAVA CEMERLANG BATAM," vol. 8, no. $1,2020$. 